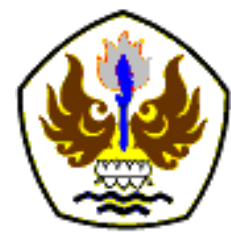

INFOMATEK

Volume 22 Nomor 1 Juni 2020

\title{
RANCANG BANGUN MICROBUBBLE GENERATOR TIPE ORIFICE DENGAN PIPA POROUS UNTUK AERASI KOLAM IKAN
}

\author{
Sulistyo Sidik Purnomo ${ }^{1,{ }^{*}}$, Jojo Sumarjo ${ }^{2}$, Farradina Choria Suci ${ }^{2}$ \\ ${ }^{1}$ Program Studi Agroteknologi - Universitas Singaperbangsa Karawang \\ 2Jurusan Teknik Mesin - Universitas Singaperbangsa Karawang
}

\begin{abstract}
Abstrak: Indonesia merupakan negara kepulauan dengan potensi laut yang besar. Hal ini membuat Indonesia memiliki potensi produksi akuakultur terbesar di dunia. Tantangan besar akuakultur yaitu cara meningkatkan produktivitas untuk suplai pangan, namun dengan penggunaan sumber air dan lahan yang lebih efisien. Hal tersebut tentu perlu didukung oleh pengembangan teknologi yang hemat energi serta kualitas air yang tetap terjaga pada kondisi ideal. Pada sektor perikanan, kualitas air merupakan faktor utama untuk perkembangan budidaya ikan. Penelitian ini mengkaji kapabilitas dari Microbubble Generator (MBG) tipe orifice dengan pipa porous pada aerasi kolam ikan. Nilai Dissolved Oxygen/DO merupakan indikator kerja yang digunakan untuk menguji kapabilitas MBG. Pada penelitian ini diperoleh alat uji MBG tipe orifice dengan pipa porous berdimensi overall $0,5 \mathrm{~m} \times 0,5 \mathrm{~m} \times 1,5 \mathrm{~m}$, diameter lubang porous $0,3 \mathrm{~mm}$, diameter nozzle $20 \mathrm{~mm}$, pipa $3 / 4$ inch PVC, kapasitas aliran 430liter/menit, head tekanan $18 \mathrm{~m}$. Hasil pengujian pada ukuran kolam ikan $10 \mathrm{~m} \times 2,3 \mathrm{~m} \times 1 \mathrm{~m}$ (tinggi air $85 \mathrm{~cm}$ ) dengan air standar (tanpa ikan), untuk setiap kedalaman $(30 \mathrm{~cm}$ dan $60 \mathrm{~cm}$ ) peningkatan harga DO sebanding dengan peningkatan diameter orifice. Pengaruh jarak semburan terhadap harga DO adalah berbanding terbalik, semakin jauh jarak semburan akan menurunkan harga DO. Pada variasi kedalaman, harga DO berada pada kisaran harga yang sama yaitu $8,15 \mathrm{ppm}$ sampai dengan $8,16 \mathrm{ppm}$, hal ini menunjukkan bahwa pengaruh kedalaman tidak menunjukkan perbedaan harga DO yang cukup besar. Harga DO yang terukur dari hasil pengujian dengan variasi orifice dan kedalaman adalah cukup sesuai untuk aerasi kolam ikan, karena harga DO untuk air dengan ikan sekitar 2-4 ppm.
\end{abstract}

Kata kunci: Dissolved Oxygen, Microbubble, Microbubble generator

\section{PENDAHULUAN}

Indonesia merupakan negara kepulauan dengan potensi laut yang besar, 75\% wilayahnya berupa laut (termasuk ZEEI) dan $28 \%$ wilayah daratnya berupa ekosistem perairan umum darat, hal ini membuat Indonesia memiliki potensi produksi akuakultur

\footnotetext{
*) sulistyo.sidik@staff.unsika.ac.id
}

Pertama diterima: 13 Desember 2019

Direvisi: 30 Mei 2020

Disetujui untuk publikasi: 31 Mei 2020 terbesar di dunia (Rokhmin [1]). Saat ini, terdapat tantangan besar dalam produksi akuakultur yang harus diselesaikan yaitu cara meningkatkan produktivitas untuk suplai pangan, namun dengan penggunaan sumber air dan lahan yang lebih efisien (Direktorat Jenderal Perikanan Budidaya [2]). Pada sektor perikanan, budidaya ikan yang dilakukan di darat akan diupayakan untuk memanfaatkan sumberdaya air terbatas atau dengan pemanfaatan teknologi tertentu tanpa adanya 
pergantian air sama sekali. Hal tersebut tentu perlu didukung oleh pengembangan teknologi yang hemat energi dan dapat menciptakan kualitas air yang tetap terjaga pada kondisi ideal untuk perkembangan budidaya ikan.

Kualitas air dalam budidaya ikan menjadi faktor yang sangat penting, sebab kualitas air yang kurang baik dapat menimbulkan stress, memicu timbulnya penyakit, dan juga dapat menyebabkan kematian pada ikan yang dibudidaya. Faktor-faktor yang mempengaruhi kualitas air dalam kegiatan akuakultur antara lain suhu air, Dissolved Oxygen (DO) atau oksigen terlarut, derajat keasaman $(\mathrm{pH})$, alkalinitas, amonia, nitrit,nitrat, karbondioksida, dan bahan organikterlarut lainnya. Kandungan oksigen terlarut (DO) minimum adalah 2 ppm dalam keadaan normal dan tidak tercemar oleh senyawa beracun. Idealnya, kandungan oksigen terlarut dan tidak boleh kurang dari 1,7 ppm selama waktu 8 jam dengan sedikitnya pada tingkat kejenuhan sebesar 70 \% (HUET [3]). KLH menetapkan bahwa kandungan oksigen terlarut adalah 5 ppm untuk kepentingan wisata bahari dan biota laut (Anonimous [4]).

Salah satu metode untuk memperbaiki kualitas air yaitu dengan meningkatkan kadar oksigen terlarut dalam air. Microbubble Generator (MBG) adalah salah satu alat yang mampu melarutkan oksigen ke dalam air melalui gelembung-gelembung udara ukuran mikro yang dihasilkannya. MBG bekerja dengan cara menaikkan kadar DO. MBG juga memiliki konstruksi yang lebih sederhana dan memiliki kemampuan penjernihan air yang lebih baik dibandingkan dengan teknologi lainnya (Sadatomi [5]).

Penelitian terkait MBG telah dilakukan, diantaranya microbubble generator swirl jet yang cara kerjanya memanfaatkan gaya setrifugal pada aliran air dan gaya sentripetal pada aliran udara sehingga terjadi swirling atau putar akibat dari perbedaan berat jenis. Perbedaan itu akan menimbulkan kavitasi secara terus menerus sehingga dihasilkannya microbubble dengan ukuran diameter 10-20 $\mu \mathrm{m}$ yang terbentuk pada outlet dari kontainer. Sadatomi dkk., (Sadatomi [6]), menemukan jenis MBG untuk memproduksi gelembunggelembung udara mikro menggunakan bentuk dari spherical body bagian dalam pipa untuk membentuk celah. Microbubble terbentuk karena aliran turbulen yang masuk ke dalam saluran dan juga akibat dari tegangan geser yang membuat udara terpecah dan berubah menjadi gelembung-gelembung berukuran mikro. Berdasarkan penelitian tersebut diperoleh rasio diameter optimal dari spherical body ke pipa adalah $\quad$ dl $D=0,865$; posisi aksial optimal dari lubang hisap udara adalah $x / d=0,42$; semakin besar generator maka semakin baik kinerjanya yaitu tenaga hidrolik 
rendah dan efisiensi pembentukan gelembung tinggi, serta generator ini terbukti dapat meningkatkan oksigen terlarut dalam air. Namun, terdapat beberapa kelemahan dari MBG tipe spherical body diantaranya kesulitan untuk menempatkan bola pejal atau spherical body di dalam saluran, selain itu proses pembuatan lubang pada dinding saluran tidak praktis. Hal tersebut mendorong Sadatomi dkk., (Sadatomi [7]) menciptakan sebuah MBG jenis baru yaitu multi-fluid mixer. Peran dari spherical body dan lubang pada dinding saluran digantikan oleh sebuah orifice dan sebuah pipa berongga atau porous pipe. Pada penelitian ini, diperoleh rasio diameter orifice ke pipa yang direkomendasikan sekitar 0,57 $\mathrm{mm}$ yang sesuai dengan jenis MBG tipe LP12.5, SF-4.0, MF-8.4 dan LF-12.5. Rasio diameter tersebut direkomendasikan, sebab rasio laju pembentukan gelembung mikro ke tingkat konsumsi daya lebih tinggi pada kedalaman air $<1,2 \mathrm{~m}$ dan tingkat pembentukan gelembung maksimum yang dapat dicapai lebih tinggi. Diameter gelembung rata-rata dan diameter gelembung rata-rata Sauter untuk MBG sekitar $0,12 \mathrm{~mm}$ dan $0,63 \mathrm{~mm}$ pada $Q_{G}=1,0 \mathrm{l} / \mathrm{mnt}$ jika kecepatan air rata-rata melalui lubang lebih tinggi dari sekitar $10 \mathrm{~m} / \mathrm{s}$. Tidak ada perbedaan yang cukup besar dari diameter gelembung yang terlihat antara $300 \mu \mathrm{m}$ punching porous dan $25 \mu \mathrm{m}$ fiber porous.
Tujuan dari penelitian ini adalah untuk perancangan dan membuat Nozzle Microbubble Generator (MBG) tipe orifice dengan pipa porous, serta menguji kapabilitas dari MBG tipe orifice dengan pipa porous pada aerasi kolam ikan. Nilai koefisien perpindahan massa volumetrik oksigen atau Dissolved Oxygen (DO) merupakan indikator kerja yang digunakan untuk menguji kapabilitas MBG pada penelitian ini. MBG tipe orifice ini memiliki desain sederhana yang mudah untuk diproduksi dan mudah dipasang. Hal ini diharapkan mampu memberikan solusi dari masalah oksigen terlarut pada budidaya ikan, serta dapat diterapkan untuk meningkatkan produktivitas hasil perikanan

\section{METODOLOGI}

Pada tahapan persiapan meliputi, studi pustaka serta persiapan alat dan bahan, Alat yang dibutuhkan antara lain pompa air jenis sentrifugal dengan daya $1.5 \mathrm{Kw}, 4301 \mathrm{l} / \mathrm{min}$, 18 meter head, flowmeter udara, flowmeter air, DO meter, dan kolam uji yang digunakan merupakan kolam permanen dengan ukuran $10 \mathrm{~m} \times 2,3 \mathrm{~m} \times 1 \mathrm{~m}$ dengan tinggi air $85 \mathrm{~cm}$ yang merupakan kolam milik Balai Riset Pemuliaan Ikan (BRPI), Jalan Raya 2 Sukamandi Pantura, Patokbeusi, Kabupaten Subang, Jawa Barat. Adapun bahan yang digunakan yaitu air standar kolam ikan dengan temperatur dan tekanan standar normal serta faktor seperti viskositas, salinitas, dan tingkat 
kekeruhan air diabaikan. Udara yang dianggap sebagai udara kering dengan kandungan di dalamnya 78,09\% nitrogen; 20,95\% oksigen; 0,93\% argon; 0,04\% karbon dioksida; dan gas-gas lain yang terdiri dari neon, helium, metana, kripton, hidrogen, xenon, ozon, radon. Bahan lainnya seperti pipa PVC, fitting pipa, ball valve, selang udara, microbubble generator menggunakan tipe orifice dengan diameter $10 \mathrm{~mm}$ dengan pipa berpori dengan diameter lubang $0,3 \mathrm{~mm}$.

\subsection{Tahapan Perancangan}

Pada tahapan perancangan dibuat skema Microbubble generator (MBG) dan nozzle MBG. Gambar 1 merupakan skema MBG yang akan diuji.

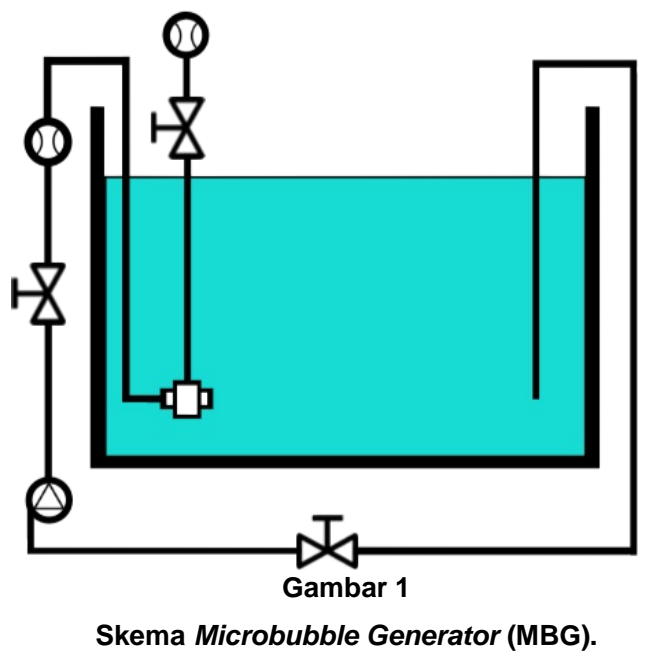

Pada penelitian ini, lebih menitik beratkan pada perancangan nozzle MBG yaitu diameter aliran air masuk dan keluar sebesar 19mm, diameter orifice sebesar $10 \mathrm{~mm}$, dan ukuran lubang pada pipa porous sebesar $0.3 \mathrm{~mm}$, sebagaimana ditunjukkan pada Gambar 2.

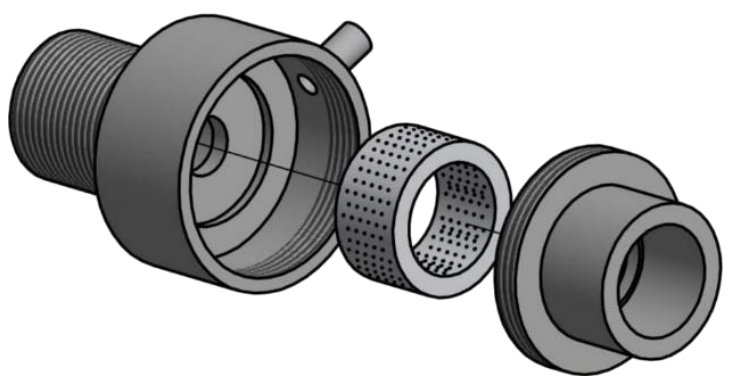

Gambar 2.

Nozzle MBG tipe orifice dengan pipa porous

\subsection{Tahapan Pengujian}

Pelaksanaan pengujian dilakukan secara eksperimen di Laboratorium Budidaya Politeknik Kelautan dan Perikanan Karawang. Pada pengujian ini memiliki tujuan sebagai berikut:

a. Mengetahui pengaruh kedalaman microbubble generator, diameter orifice, dan debit air terhadap debit udara

b. Mengetahui pengaruh debit air dan debit udara terhadap ukuran bubble yang dihasilkan

c. Mengetahu nilai oksigen terlarut yang dihasilkan microbubble generator

Gambar 3 memperlihatkan diagram alir untuk alur pelaksanaan pengujian. 


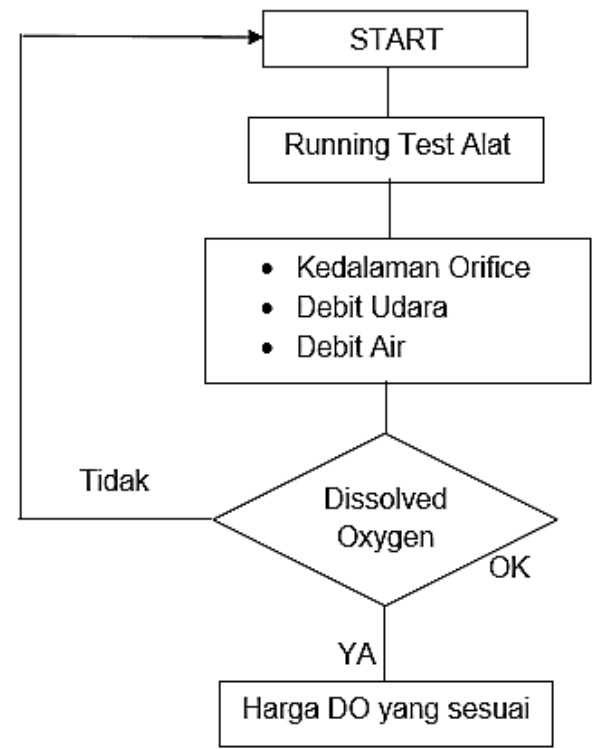

Gambar 3.

Alur pelaksanaan pengujian

\section{ANALISIS DAN PEMBAHASAN}

\subsection{Perancangan Alat}

Telah dirancang Microbubble generator (MBG) tipe orifice dengan pipa porous untuk aerasi kolam ikan dengan langkah perancangan ditunjukkan pada Gambar 4. Sesuai dengan Gambar 4, maka ditentukan dimensi dari alat ini sebagai berikut.

1. Overall size: $0,5 \mathrm{~m} \times 0,5 \mathrm{~m} \times 1,5 \mathrm{~m}$

2. Pipe size: $3 / 4$ inchi ; bahan pvc

3. Valve size: $3 / 4$ inchi ; bahan pvc ; ball valve

4. Flowmeter size (air): 3/4 inchi

5. Flowmeter size (udara): $3 / 4$ inchi

6. Pressure gauge: $3 / 8$ inch ; 2,5 bar

7. Pump size: $0.25 \mathrm{~m} \times 0.25 \mathrm{~m} \times 0.5 \mathrm{~m}$

8. Orifice size: $8 \mathrm{~mm}$ dia, $10 \mathrm{~mm}$ dia, $12 \mathrm{~mm}$ dia, $14 \mathrm{~mm}$ dia
9. Pipa porous: $0.3 \mathrm{~mm}$ dia

Kapasistas pompa dipilih dan disesuaikan dengan kecepatan produksi microbubble yaitu 430 liter/menit dengan tekanan 1.8 bar dan tipe pompanya adalah submersible pump, sedangkan flow meternya dipilih tipe rotameter. Pipa dengan bahan PVC adalah kuat untuk menahan tekanan pompa sebesar 1,8 bar, karena kekuatan pipanya adalah 4 bar. Adapun design drawing dari Microbubble generator ditunjukkan pada Gambar 5.

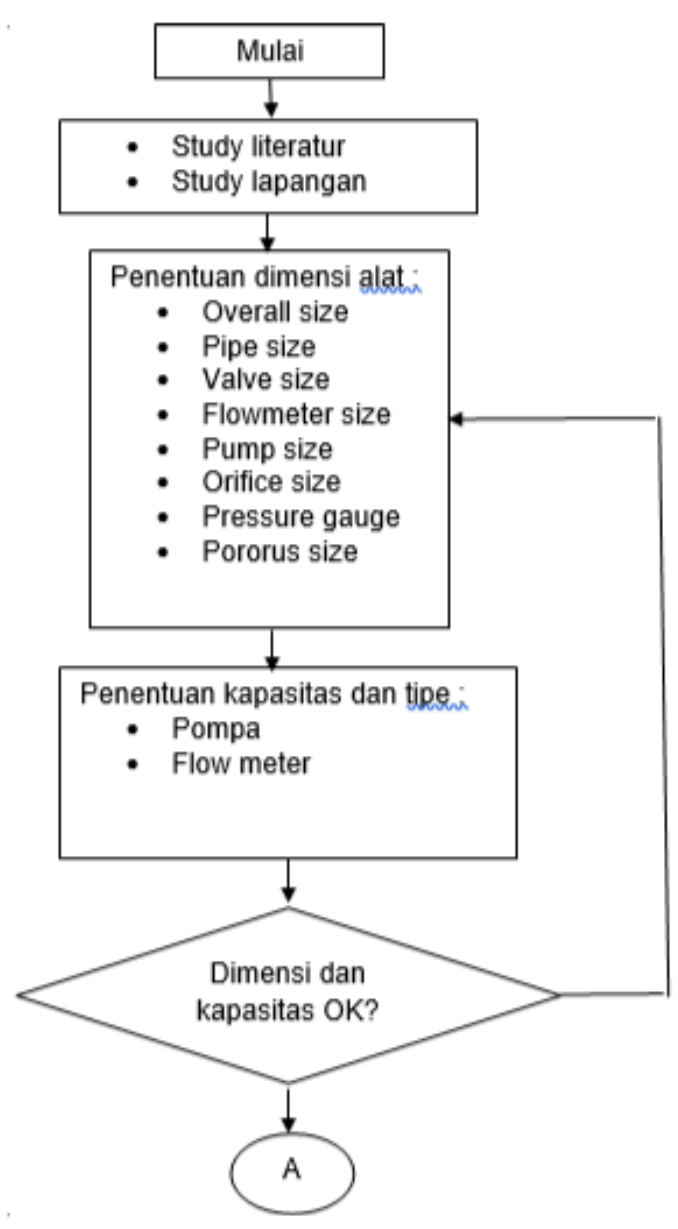




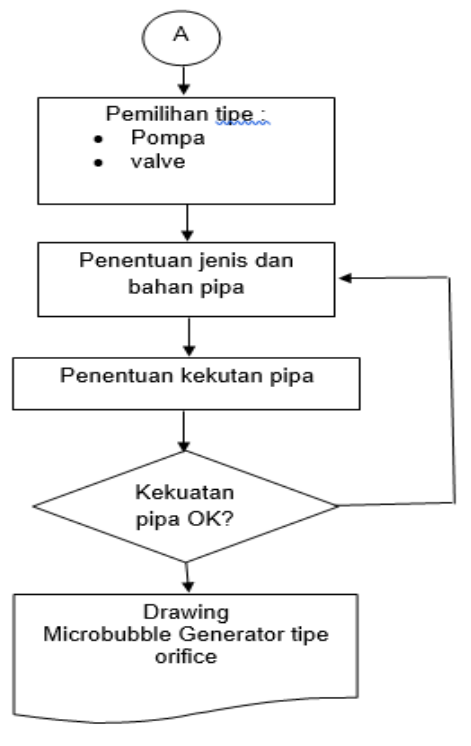

Gambar 4.

Alur perancangan alat MBG

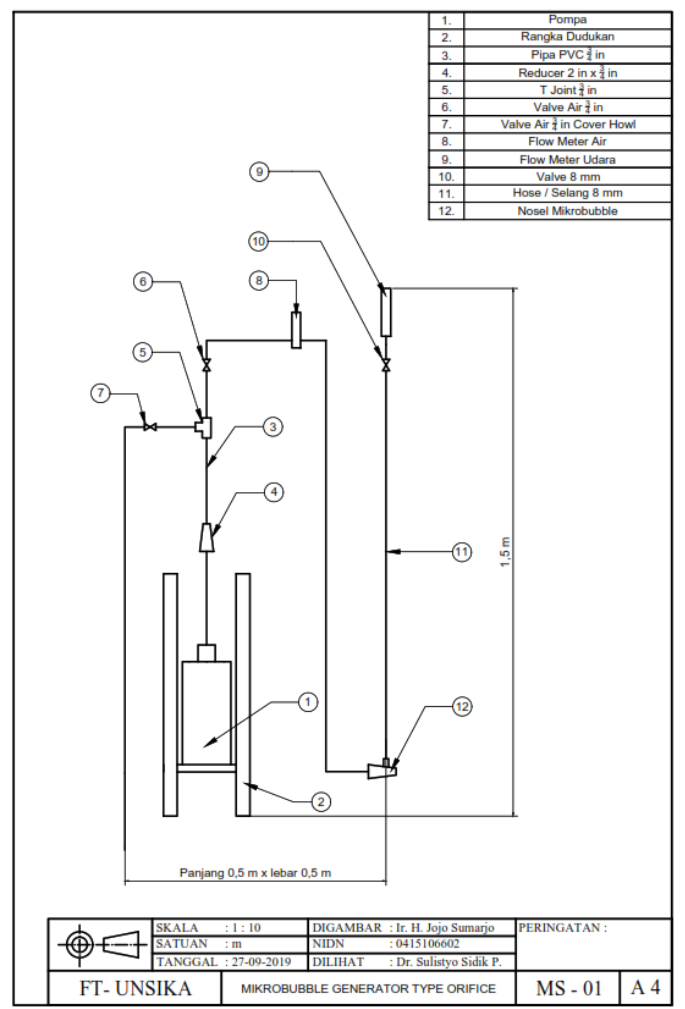

Gambar 5.

Drawing dari MBG

\subsection{Pembuatan Alat}

Langkah pembuatan alat Microbubble generator ditunjukkan pada Gambar 6.

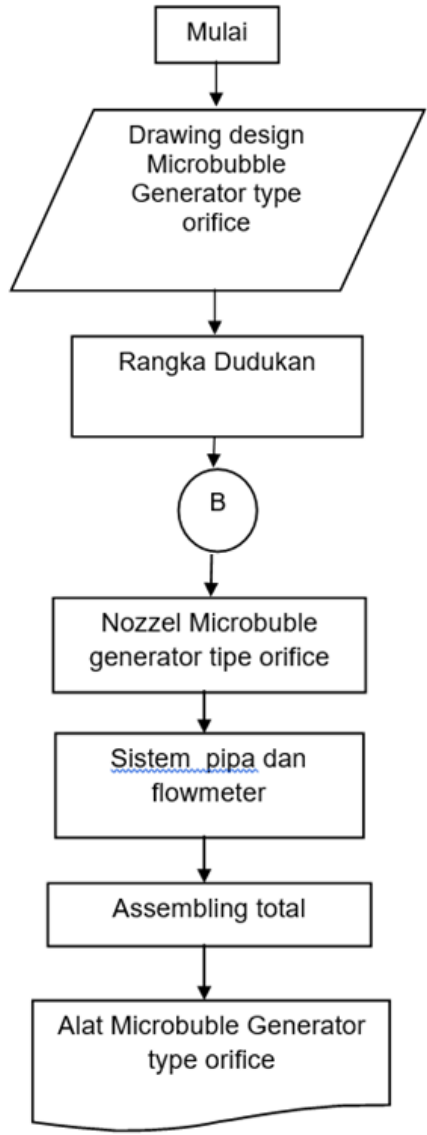

Gambar 6.

Alur pembuatan alat MBG

\subsection{Pengujian Alat}

Setelah alat MBG dilakukan assembling total, kemudian dilakukan function test yang bertujuan untuk memeriksa fungsi alat tersebut. Function test ini dilakukan di kolam renang selama 3 jam, alat ini di running dengan variasi bukaan katup air dan angin. Setelah alat MBG berfungsi dengan baik, 

dengan Pipa Porous untuk Aerasi Kolam Ikan

kemudian dilakukan uji sebenarnnya yaitu di kolam ikan (tanpa ada ikan) di Balai Riset pemuliaan Ikan (BRPI), Patokbeusi, Kabupaten Subang, Jawa Barat.

Data dari hasil pengujiannya sebagai berikut.

1. Temperatur: $31-33{ }^{\circ} \mathrm{C}$

2. Diameter dalam orifice: $8 \mathrm{~mm}, 10 \mathrm{~mm}$, $12 \mathrm{~mm}$, dan $14 \mathrm{~mm}$

3. Alat microbubble generator

4. DO-meter type DO-5510 merk Lutron

5. Kolam uji berukuran: $10 \mathrm{~m} \times 2,3 \mathrm{~m} \times 1 \mathrm{~m}$ (tinggi air $85 \mathrm{~cm}$ )

6. Air adalah standard kolam ikan nila (tanpa ikan) dengan DO-awal sebesar 7,2 - 7,4 ppm

7. Bukaan katup (valve opening) air maksimum dengan Qa ( laju aliran udara) sebesar 0,3 Ipm (konstan)

\subsection{Harga Dissolved Oxygen (DO)}

Pada penelitian ini, nilai koefisien perpindahan massa volumetrik oksigen atau Dissolved Oxygen (DO) merupakan indikator kerja yang digunakan untuk menguji kapabilitas MBG. Besaran harga DO ini dapat menentukan kualitas air dalam kolam agar tetap terjaga pada kondisi ideal untuk perkembangan budidaya ikan. Berikut ini terdapat harga DO hasil uji pada variasi kedalaman 30 dan $60 \mathrm{~cm}$ (dari permukaan air di kolam uji) dengan ukuran diameter dalam orifice $8 \mathrm{~mm}, 10 \mathrm{~mm}$, $12 \mathrm{~mm}$, dan $14 \mathrm{~mm}$.

\subsubsection{Harga DO hasil uji pada kedalaman 30 cm (dari permukaan air di kolam uji) dengan ukuran diameter dalam orifice 8 $\mathrm{mm}, 10 \mathrm{~mm}, 12 \mathrm{~mm}, 14 \mathrm{~mm}$}

Pada Gambar 7 memperlihatkan grafik perubahan nilai Dissolved Oxygen (DO) untuk waktu yang berbeda dengan empat variasi diameter dalam orifice pada kedalaman 30 $\mathrm{cm}$. Pada grafik ditunjukkan harga DO maksimum sebesar 9,4 ppm dan minimum sebesar 9 ppm untuk diameter orifice $14 \mathrm{~mm}$ pada jarak semburan $150 \mathrm{~cm}$ dari nozzle microbubble. Pada diameter orifice $8 \mathrm{~mm}$, harga DO maksimum bisa dicapai sebesar 7,7 ppm dan harga minimumnya sebesar 7,3 ppm (hal ini sama dengan DO awal air sebelum diuji) karena indikasi flowmeter udara adalah nol (no reading).

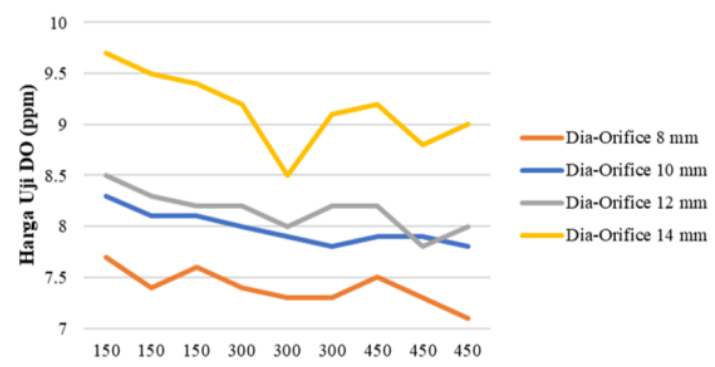

Gambar 7.

Harga DO-jarak untuk setiap diameter orifice pada kedalam $30 \mathrm{~cm}$

Peningkatan harga DO yang ditunjuukan sebanding dengan peningkatan diameter orifice. Diameter orifice yang kecil menghasilkan harga DO yang rendah, sedangkan dimeter orifice semakin besar 
maka harga DO akan semakin meningkat. Adapun untuk pengaruh jarak semburan (untuk setiap diameter orifice yang berbeda) terhadap harga DO adalah berbanding terbalik, semakin jauh jarak semburan akan menurunkan harga DO.

3.4.2 Harga DO hasil uji pada kedalaman 60 cm (dari permukaan air di kolam uji) dengan ukuran diameter dalam orifice 8 $\mathrm{mm}, 10 \mathrm{~mm}, 12 \mathrm{~mm}$, dan $14 \mathrm{~mm}$

Pada Gambar 8 memperlihatkan grafik perubahan nilai Dissolved Oxygen (DO) untuk waktu yang berbeda dengan empat variasi diameter dalam orifice pada kedalaman 60 $\mathrm{cm}$. Pada grafik ditunjukkan harga DO maksimum sebesar 9,4 ppm dan minimum sebesar 8,5 ppm untuk diameter orifice $14 \mathrm{~mm}$ pada jarak semburan $150 \mathrm{~cm}$ dari nozzle microbubble. Pada diameter orifice $8 \mathrm{~mm}$, harga DO maksimum bisa dicapai sebesar 7,9 ppm dan harga minimumnya sebesar 7,3 ppm (ini sama dengan DO awal air sebelum diuji) karena indikasi flowmeter udara adalah nol (no reading).

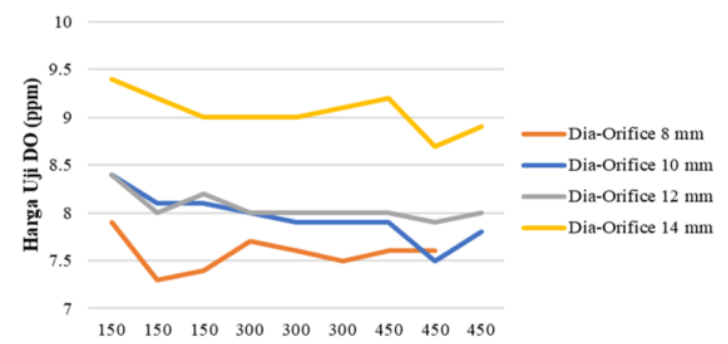

Gambar 8.

Harga DO-jarak untuk setiap diameter orifice pada kedalam $60 \mathrm{~cm}$
Peningkatan harga DO sebanding dengan peningkatan diameter orifice, diameter orifice yang kecil menghasilkan harga DO yang rendah, sedangkan diameter orifice semakin besar maka harga DO akan semakin meningkat. Sedangkan pengaruh jarak semburan (untuk setiap diameter orifice yang berbeda) terhadap harga DO adalah berbanding terbalik, semakin jauh jarak semburan akan menurunkan harga DO, tapi pada kedalaman $60 \mathrm{~cm}$ ini, penurunan harganya tidak begitu curam seperti pada kedalaman $30 \mathrm{~cm}$.

Harga DO rata-rata pada kedalaman $30 \mathrm{~cm}$ berada pada kisaran 8,15 ppm, sedangkan harga DO rata-rata pada kedalaman $60 \mathrm{~cm}$ berada pada kisaran 8,16 ppm. Untuk setiap kedalaman harga DO berada pada kisaran harga yang sama yaitu 8,15 ppm sampai dengan 8,16 ppm. Hal ini menunjukkan bahwa pengaruh kedalaman tidak menunjukkan perbedaan harga DO yang cukup besar dan menunjukkan pada kisaran harga DO yang sama. Pada kedalaman $30 \mathrm{~cm}$ (untuk setiap diameter orifice dan jarak semburan) kurvanya cukup curam menurun, sedangkan pada kedalaman $30 \mathrm{~cm}$ (untuk setiap diameter orifice dan jarak semburan) kurvanya cenderung cukup landai. Hal ini menunjukkan bahwa stabilitas harga DO sebanding dengan kedalaman, semakin dalam harga DO semakin stabil (menunjukkan harga yang 
sama). Hal ini dikarenakan microbubble lambat untuk mencapai permukaan air.

Berdasarkan data diatas, dapat disimpulkan bahwa harga DO yang terukur dari hasil pengujian dengan variasi orifice dan kedalaman adalah cukup sesuai untuk aerasi kolam ikan, karena harga DO untuk air dengan ikan sekitar 2 ppm dengan 4 ppm

\section{IV.KESIMPULAN}

1. Telah dirancang dan dibuat Aalat uji Microbubble Generator Tipe Orifice dengan Pipa Porous uanuk Aerasi Kolam Ikan, dengan dimensi overall $0,5 \mathrm{~m} \times 0,5 \mathrm{~m} \times 1,5$ $\mathrm{m}$, diameter lubang pororus $0,3 \mathrm{~mm}$, diameter nozzle $20 \mathrm{~mm}$, pipa $3 / 4$ inch PVC, kapasitas aliran 430 liter/menit, head tekanan 18 meter.

2. Hasil pengujian pada ukuran kolam ikan 10 $\mathrm{m} \times 2,3 \mathrm{~m} \times 1 \mathrm{~m}$ (tinggi air $85 \mathrm{~cm}$ ) dengan air standar (tanpa ikan) kolam untuk ikan nila, Untuk setiap kedalaman $(30 \mathrm{~cm}$ dan $60 \mathrm{~cm}$ ) peningkatan harga DO sebanding dengan peningkatan diameter orifice, diameter orifice yang kecil menghasilkan harga DO yang rendah, sedangkan dimeter orifice semakin besar maka harga DO akan semakin meningkat.

3. Pengaruh jarak semburan (untuk setiap diameter orifice yang berbeda) terhadap harga DO adalah berbanding terbalik, semakin jauh jarak semburan akan menurunkan harga DO.

4. Pada setiap kedalaman harga DO berada pada kisaran harga yang sama yaitu 8,15 ppm sampai dengan 8,16 ppm. Hal ini menunjukan bahwa pengaruh kedalaman tidak menunjukan perbedaan harga DO yang cukup besar dan menunjukan pada kisaran harga DO yang sama.

5. Harga DO yang terukur dari hasil pengujian dengan variasi orifice dan kedalaman adalah cukup sesuai untuk aerasi kolam ikan.

\section{UCAPAN TERIMAKASIH}

Ucapan terimakasih disampaikan kepada Universitas Singaperbangsa Karawang melalui Hibah Penelitian Lintas Fakultas dengan nomor kontrak penelitian 1826/SP2H/UN64/PP/2019. Penulis juga mengucapkan terimakasih kepada Tim Balai Riset Pemuliaan Ikan (BRPI), Patokbeusi, Kabupaten Subang, Jawa Barat khusunya kepada kelompok Peneliti Ikan Nila, Dr. Ir. Bambang Gunadi, M.Sc dan tim, serta semua pihak yang telah berperan dalam penelitian ini.

\section{DAFTAR PUSTAKA}

[1] Rokhmin D. Membangunkan Raksasa Ekonomi Akuakultur yang Tertidur, 11 Juli 2019, 10:43 [diakses 25 Mei 2020]. Tersedia dari: https://www.kompasiana.com/rdteam1 
/5d26af470d8230496f415542/memban

gunkan-raksasa-ekonomi-akuakultur- yang-

tertidur?page=all

[2] Direktorat Jenderal Perikanan Budidaya, Teknologi Akuakultur Jawaban Hadapi Tantangan Krisis Air dan Pangan, 25 Maret 2018 [diakses 25 Mei 2020]). Terdapat dari https://kkp.go.id/djpb/artikel/3131-teknologiakuakultur-jawaban-hadapi-tantangankrisis-air-dan-pangan

[3] (HUET, H.B.N, Water Quality Criteria for Fish Life Biological Problems in Water Pollution, PHS. Publ. No.999-WP-25, pp.160-167, 1970.

[4] Anonimous, Keputusan Menteri Negara Lingkungan Hidup No.51 Tahun 2004. Tentang: Baku Mutu Air Laut, hal. 11, 2004.

[5] Sadatomi, M, Kawahara, A. Matsuyama, F. and Kimura, T., "An Advanced Microbubble Generator and its Application To A Newly Developed Bubble-Jet Type Airlift Pump", Multiphase Science and Technology, vol. 19, pp. 323-342, 2007.
[6] Sadatomi, M. Kawahara, A. Kano, K. and Ohtomo, A., "Performance of New MicroBubble Generator With A Sperical Body in Flowing Water Tube", Experimental Thermal and Fluid Science, vol. 29, pp. 615-623, 2005.

[7] Sadatomi, M. Kawahara, A. Matsuura, H. and Shikatani, S., "Microbubble Generation Rate and Bubble Dissolution Rate Into Water by A Simple Multi Fluid Mixer With Orifice and Porous Tube", Experimental Thermal and Fluid Science, vol. 41, pp. 2330, 2012. 